\title{
Gender differences in the clinical presentation, treatment and outcomes of acute myocardial infarction
}

\section{Spolne razlike u kliničkoj prezentaciji, liječenju i ishodima akutnog infarkta miokarda}

\author{
Davor Horvat ${ }^{1 *}$, Josip Vincelj ${ }^{2}$, Kristina Bakale ${ }^{1}$, Mario Tesla ${ }^{3}$
}

\begin{abstract}
Aim: To assess the epidemiological and clinical differences between men and women with acute myocardial infarction (AMI). Patients and methods: This retrospective study included 579 patients (352 men and 221 women) who were hospitalized at the Coronary and postcoronary unit at the General Hospital, Karlovac, Croatia, from 2013 to 2016. We determined the frequency, patient's age, type of symptoms, cardiovascular risk the factors, localization, the time from the onset of symptoms to arrival to the hospital, treatment and complications during the hospitalization. Results: AMI is more frequent in men than in women $(P<0.001)$ and in men it is significantly more likely to occur at an earlier age than in women $(P<0.001)$. Men often have typical symptoms while women have atypical symptoms $(P=0.045)$. More often women have arterial hypertension $(P=0.017)$ and diabetes $(P=0.025)$, while men are more often smokers $(P=0.001)$. There was no difference between the gender regarding hyperlipidemia $(P=0,674)$. Distribution of localization $(P=0.608)$, the time required for the arrival to the hospital $(P=0.399)$ and all the complications of $\mathrm{AMI}$ are equal $(P=0.365)$. Men are more likely to receive $\mathrm{PCl}$ treatment, while women get the conservative therapy $(P=0.007)$. Conclusion: Compared with other studies, our women with AMI have less hyperlipidemia and do not come later to hospital than men. Possible causes are dietary habits and genetics or education and good organization of outpatient emergency medical assistance.
\end{abstract}

Key words: acute myocardial infarction; cardiovascular risk; Croatia; hospital treatment

\author{
${ }^{1}$ Department of internal medicine, \\ General Hospital Karlovac, Karlovac \\ ${ }^{2}$ Department of Cardiology, University \\ Hospital Dubrava, Zagreb \\ ${ }^{3}$ Dislocated professional nursing study in \\ Karlovac, University of Rijeka, Rijeka
}

\author{
*Corresponding author: \\ Davor Horvat, MD, PhD \\ Department of Cardiology \\ General Hospital Karlovac \\ Andrija Štampar 3, 47000 Karlovac, Croatia \\ e-mail: davor.horvat@ka.t-com.hr
}




\section{INTRODUCTION}

Cardiovascular diseases are currently the leading cause of death in industrialized countries and are expected to become so in emerging countries by 2020. Among these, coronary artery disease (CAD) is the most prevalent manifestation and is associated with high mortality and morbidity ${ }^{1}$.

Age is the dominant driver of cardiovascular risk, and most individuals are already at very high risk at the age of 65 years. Many preventive trea-

Acute myocardial infarction is different in clinical presentation, diagnosis and treatment. In recent years there have been some differences in both sexes. It is important to see possible age differences, risk factors, time of arrival in the hospital, symptoms and conservative or invasive treatment.

tments are still effective at advanced age in terms of postponing morbidity and mortality ${ }^{2}$.

Historically, the description of symptoms associated with acute myocardial infarction (AMI) was based on the presentation characteristics of men. Women's symptoms of AMI are often labeled as "atypical" and different from the "classic" symptoms noted in men $^{3,4}$ and include a constellation of associated symptoms, usually without chest pain or discomfort ${ }^{5-8}$.

High blood pressure (BP) is a leading risk factor for disease burden globally, accounting for 9.4 million deaths and $7.0 \%$ of global disability-adjusted life-years (DALYs) in 2010 ${ }^{9}$. Elevated BP is a risk factor for $C A D$, heart failure (HF), cerebrovascular disease (CVD), periferal arterial disease (PAD), chronic kidney disease (CKD) and atrial fibrillation (AF). The risk of death from either CAD or stroke increases progressively and linearly from BP levels as low as $115 \mathrm{mmHg}$ systolic and $75 \mathrm{mmHg}$ diastolic upwards ${ }^{10}$.

People with diabetes mellitus (DM) are on average at double risk of CVD ${ }^{11}$. There is mounting evidence for a very high relative risk in younger individuals with type 2 DM (age < 40 years), and additional guidance on care is needed ${ }^{12}$.

Smoking is an established cause of a plethora of diseases and is responsible for $50 \%$ of all avoida- ble deaths in smokers, half of these due to CVD. The 10-year fatal CVD risk is approximately doubled in smokers. The BP in smokers $<50$ years of age is five-fold higher than in non-smokers ${ }^{13}$.

The crucial role of dyslipidaemia, especially hypercholesterolaemia, in the development of CVD is documented beyond any doubt by genetic, pathology, observational and intervention studies ${ }^{14}$.

The impact of AMI localization on complications is also unclear. In general, large studies analyzed the occurrence of complications in the post infarction period by anterior or inferior localization but, the results are contradictory ${ }^{15}$.

Accurate recognition of the symptoms of $A M I$ in both men and women is crucial for the inability of health care providers to recognize an evolving AMI which may lead to an incorrect diagnosis and delays in treatment ${ }^{16}$.

For patients with the clinical presentation of AMI within $12 \mathrm{~h}$ after symptom onset and with persistent ST-segment elevation or new or presumed new left bundle-branch block, early mechanical or pharmacological reperfusion should be performed $^{17}$.

Complications of AMI include mechanical, arrhythmic, ischemic, and inflammatory (early pericarditis and post-AMI syndrome) sequelae, as well as left ventricular mural thrombus. The onset of each of these complications usually results in explicit symptoms and physical manifestations. Thus, a basic knowledge of the complications that occur in the postinfarction period and the clinical syndromes associated with each, will allow the physician to evaluate and treat the complication appropriately ${ }^{18 .}$

Our objective was to investigate the presence of epidemiological and clinical differences between men and women with AMI. It will also examine the incidence, patient's age, the type of symptoms, cardiovascular risk factors, localization, time from symptom onset to arrival at the hospital, treatment and complications during hospitalization of AMI.

\section{PATIENTS}

A retrospective study was conducted in the period from 2013 to 2016. The study included 579 patients. The patient's age ranged from 32 to 86 
years, and the average age was 62.5 years. There were 352 men (60.8\%) and 221 (39.2\%) women. All patients were hospitalized in the coronary and postcoronary unit in the General Hospital, Karlovac, Croatia. The patients with AMI were divided into two main groups according to gender. The study examined the incidence, characteristics of symptoms (typical and atypical), the incidence of arterial hypertension $(\mathrm{AH})$, diabetes, smoking and hyperlipidemia, localization (anteroseptal, anterolateral, inferior, posterior, and without ST elevation), the time from onset of symptoms to arrival at the hospital (< 6 hours, 6-12 hours, > 12 hours), treatment (mechanical or conservative therapy) and complications (LVEF $<50 \%$, aneury$\mathrm{sm}$, mural thrombus, pericardial effusion, heart failure, death) of AMI.

\section{METHODS}

The criteria for inclusion of patients were that the AMI was primary diagnosis of hospital admission.

Diagnostic criteria for AMI were chest pain, electrocardiogram (ECG) changes and troponin elevation. ECG had to have the appearance of ST segment elevation of at least $1 \mathrm{~mm}$ in anteroseptal leads (V1-V4), anterolateral leads (V3-V6), inferior leads (D2, D3, aVF), in posterior leads ST-denivelation in V3-V4 and R-wave enlargement in V1-V3 leads and T wave inversion or ST depression for non-ST elevation myocardial infarction (NSTEMI).

The cardiac enzyme troponin $\mathrm{T}$ had to be $>1.00$ $\mathrm{g} / \mathrm{L}$. Low molecular weight heparin (LMWH), alteplase, beta-blocker, acetylsalicylic acid (ASA), angiotensin converting enzyme inhibitor (ACE-i) and statin were used as conservative therapy and in percutaneus coronary intervention ( $\mathrm{PCl}$ ) additionally clopidogrel or ticagrelor. $\mathrm{PCl}$ procedure had to be with stent implantation. Left ventricular ejection fraction (LVEF) was assessed with the heart ultrasound (Simpson biplane technique in the apical projection). Complications of AMI were verified by ultrasound of the heart and by $\mathrm{x}$-ray imaging of the heart and lungs.

\section{STATISTICS}

This research is explorative. The goal is to identify all potential interaction of variables and differences between groups. The theoretical frequencies are based on the assumption (null hypothesis) that the differences will not be ${ }^{19}$. Data analysis was performed using Chi-square test. The P-value limit is 0,05. Data is processed in SPSS 20.0.

\section{RESULTS}

Chi-square test indicates that men more often have $A M I$ than women $(\chi 2=26.986 ; P<0.001)$ (table 1 ), have AMI at an earlier age than women $(\chi 2=21.327 ; \mathrm{P}<0.001)$ (table 2$)$ and have typical

Table 1. The incidence of acute myocardial infarction by gender

\begin{tabular}{|l|c|c|c|}
\hline & Men & Women & Total frequencies \\
\hline Frequencies & 352 & 227 & \\
\hline Percentage & 60.8 & 39.2 & 579 \\
\hline The expected frequency & 289.5 & 289.5 & \\
\hline Expected percentage & 50 & 50 & \\
\hline
\end{tabular}

Table 2. Acute myocardial infarction by age and gender

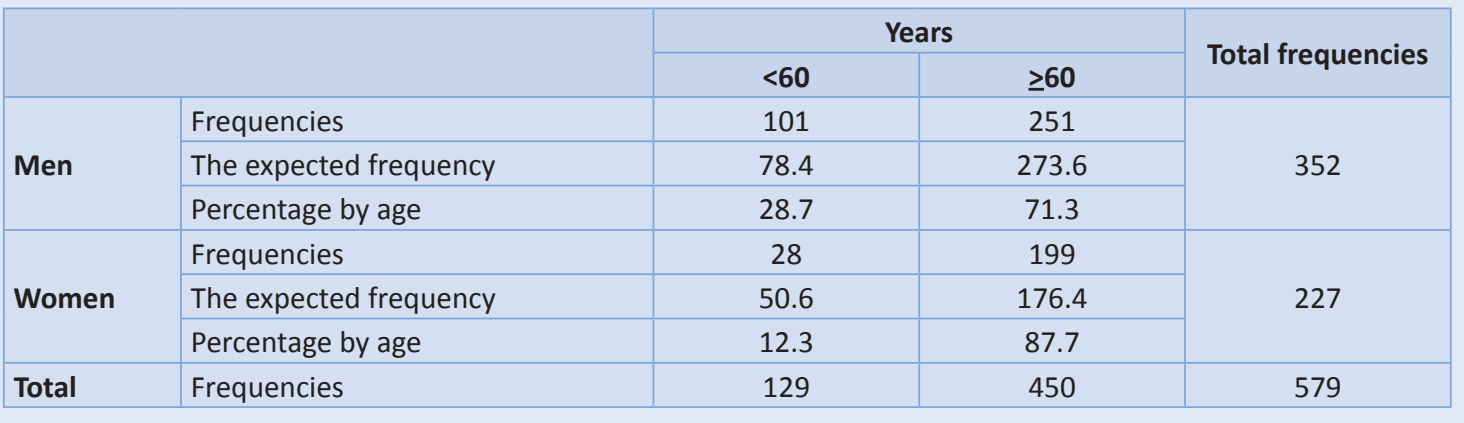


symptoms in AMI more often than women, while women have atypical symptoms ( $\chi 2=4.028 ; \mathrm{P}=$ $0.045)$ (table 3$)$. Women more often have $\mathrm{AH}(\chi 2$ $=5.685 ; P=0.017)$ (table 4$)$ and diabetes $(\chi 2=$ 5.053; $P=0.025$ ) than men (table 5). Men are more often smokers than women ( $\chi 2=11.791$; $P$ $=0.001$ ) (table 6). Chi-square test indicates equal frequency of hyperlipidaemia by gender $(\chi 2=$ $0.117 ; P=0.674$ ) (table 7), equal distribution of
AMI localization by gender $(\chi 2=2.708 ; P=0.608)$ (table 8 ) and equal distribution of arrival times to the hospital in AMI by gender ( $\chi 2=1.839$; $P=0.399$ ) (table 9). Chi-square test also indicates that in $\mathrm{AMI}$ men more often receive $\mathrm{PCl}$ treatment, while women receive conservative therapy ( $\chi 2$ = 7.395; $P=0.007$ ) (table 10). Test indicates equal distribution of all AMI complications by gender ( $\chi 2=5.440 ; P=0.365)$ (table 11).

Table 3. Typical and atypical symptoms of acute myocardial infarction by gender

\begin{tabular}{|l|l|c|c|c|}
\hline \multirow{2}{*}{} & & \multicolumn{2}{c|}{ Symptoms } & \multirow{2}{*}{ Total frequencies } \\
\cline { 3 - 5 } & Frequencies & Typical & Atypical & \\
\hline \multirow{3}{*}{ Men } & The expected frequency & 244 & 108 & \multirow{2}{*}{352} \\
\cline { 2 - 5 } & Percentage by age & 232.8 & 119.2 & \\
\hline \multirow{3}{*}{ Women } & Frequencies & 69.3 & 30.7 & \multirow{2}{*}{227} \\
\cline { 2 - 5 } & The expected frequency & 139 & 76.8 & \\
\cline { 2 - 5 } & Percentage by age & 150.2 & 38.8 & \\
\hline \multirow{2}{*}{ Total } & Frequencies & 61.2 & 196 & \\
\hline
\end{tabular}

Table 4. The incidence of arterial hypertension by gender in acute myocardial infarction

\begin{tabular}{|c|c|c|c|c|}
\hline & & \multicolumn{2}{|c|}{$\mathbf{A H}$} & \multirow{2}{*}{ Total frequencies } \\
\hline & & Yes & No & \\
\hline \multirow{3}{*}{ Men } & Frequencies & 260 & 92 & \multirow{3}{*}{352} \\
\hline & The expected frequency & 271.8 & 80.2 & \\
\hline & Percentage by age & 73.9 & 26.1 & \\
\hline \multirow{3}{*}{ Women } & Frequencies & 187 & 40 & \multirow{3}{*}{227} \\
\hline & The expected frequency & 175.2 & 51.8 & \\
\hline & Percentage by age & 82.4 & 17.6 & \\
\hline Total & Frequencies & 447 & 132 & 579 \\
\hline
\end{tabular}

$\mathrm{AH}$ - arterial hypertension

Table 5. The incidence of diabetes by gender in acute myocardial infarction

\begin{tabular}{|l|l|c|c|c|}
\hline \multirow{2}{*}{} & & \multicolumn{2}{|c|}{ Diabetes } & \multirow{2}{*}{ Total frequencies } \\
\cline { 3 - 5 } & Frequencies & Yes & No & \\
\hline \multirow{3}{*}{ Men } & The expected frequency & 112 & 240 & \multirow{2}{*}{352} \\
\cline { 2 - 5 } & Percentage by age & 124.6 & 227.4 & \\
\hline \multirow{3}{*}{ Women } & Frequencies & 31.8 & 68.2 & \multirow{2}{*}{227} \\
\cline { 2 - 5 } & The expected frequency & 93 & 134 & \\
\cline { 2 - 5 } & Percentage by age & 80.4 & 59.0 & \\
\hline \multirow{2}{*}{ Total } & Frequencies & 41.0 & 374 & \\
\hline
\end{tabular}


Table 6. The incidence of smoking by gender in acute myocardial infarction

\begin{tabular}{|c|c|c|c|c|}
\hline & & \multicolumn{2}{|c|}{ Smoking } & \multirow{2}{*}{ Total frequencies } \\
\hline & & Yes & No & \\
\hline \multirow{3}{*}{ Men } & Frequencies & 123 & 229 & \multirow{3}{*}{352} \\
\hline & The expected frequency & 104.6 & 247.4 & \\
\hline & Percentage by age & 34.9 & 65.1 & \\
\hline \multirow{3}{*}{ Women } & Frequencies & 49 & 178 & \multirow{3}{*}{227} \\
\hline & The expected frequency & 67.4 & 159.6 & \\
\hline & Percentage by age & 21.6 & 78.4 & \\
\hline Total & Frequencies & 172 & 407 & 579 \\
\hline
\end{tabular}

Table 7. The incidence of hyperlipidemia by gender in acute myocardial infarction

\begin{tabular}{|l|l|c|c|c|}
\hline \multirow{2}{*}{} & \multirow{2}{*}{} & \multicolumn{2}{|c|}{ Hyperlipidemia } & \multirow{2}{*}{ Total frequencies } \\
\cline { 3 - 5 } & Frequencies & Yes & No & \\
\hline \multirow{3}{*}{ Men } & The expected frequency & 166 & 186 & \multirow{2}{*}{352} \\
\cline { 2 - 5 } & Percentage by age & 163.5 & 52.8 & \\
\hline \multirow{3}{*}{ Women } & Frequencies & 47.2 & 124 & \multirow{2}{*}{227} \\
\cline { 2 - 5 } & The expected frequency & 103 & 121.5 & \\
\cline { 2 - 5 } & Percentage by age & 105.5 & 54.6 & \\
\hline \multirow{2}{*}{ Total } & Frequencies & 45.4 & 310 & 579 \\
\hline
\end{tabular}

Table 8. Distribution of localization of acute myocardial infarction by gender

\begin{tabular}{|c|c|c|c|c|}
\hline \multicolumn{2}{|c|}{ Localization of AMI } & \multirow[t]{2}{*}{ Men } & \multirow[t]{2}{*}{ Women } & Total frequencies \\
\hline \multirow{3}{*}{ Anteroseptal } & Frequencies & & & \multirow{3}{*}{111} \\
\hline & The expected frequency & 67.7 & 43.3 & \\
\hline & Percentage by age & 59.5 & 40.5 & \\
\hline \multirow{3}{*}{ Anterolateral } & Frequencies & 19 & 13 & \multirow{3}{*}{32} \\
\hline & The expected frequency & 19.5 & 12.5 & \\
\hline & Percentage by age & 59.4 & 40.6 & \\
\hline \multirow{3}{*}{ Inferior } & Frequencies & 65 & 30 & \multirow{3}{*}{95} \\
\hline & The expected frequency & 57.9 & 37.1 & \\
\hline & Percentage by age & 68.4 & 31.6 & \\
\hline \multirow{3}{*}{ Posterior } & Frequencies & 79 & 52 & \multirow{3}{*}{131} \\
\hline & The expected frequency & 79.9 & 51.1 & \\
\hline & Percentage by age & 60.3 & 39.7 & \\
\hline \multirow{3}{*}{ NSTEMI } & Frequencies & 118 & 82 & \multirow{3}{*}{200} \\
\hline & The expected frequency & 122.0 & 78.0 & \\
\hline & Percentage by age & 59.0 & 41.0 & \\
\hline Total & Frequencies & 347 & 222 & 569 \\
\hline
\end{tabular}

AMI - acute myocardial infarction; NSTEMI - non-ST elevation myocardial infarction 
Table 9. The time from onset of acute myocardial infarction symptoms to arrival at the hospital by gender

\begin{tabular}{|l|l|c|c|c|}
\hline \multicolumn{2}{|c|}{ The time to arrival at the hospital } & Men & Women & Total frequencies \\
\hline \multirow{4}{*}{$<6$ hours } & Frequencies & 99 & 56 & \multirow{2}{*}{155} \\
\cline { 2 - 5 } & The expected frequency & 94.2 & 60.8 & \\
\cline { 2 - 5 } & Percentage by age & 63.9 & 86.1 & \multirow{2}{*}{186} \\
\hline \multirow{4}{*}{6 to 12 hours } & Frequencies & 106 & 72.9 & \\
\cline { 2 - 5 } & The expected frequency & 113.1 & 43.0 & \\
\cline { 2 - 5 } & Percentage by age & 57.0 & 91 & \multirow{2}{*}{238} \\
\hline \multirow{3}{*}{$>12$ hours } & Frequencies & 147 & 93.3 & \\
\hline & The expected frequency & 144.7 & 38.2 & \\
\cline { 2 - 5 } & Percentage by age & 61.8 & 227 & 576 \\
\hline
\end{tabular}

Table 10. Treatment of acute myocardial infarction by gender

\begin{tabular}{|c|c|c|c|c|}
\hline & & \multicolumn{2}{|c|}{ Treatment } & \multirow{2}{*}{ Total frequencies } \\
\hline & & Conservative & $\mathrm{PCl}$ & \\
\hline \multirow{3}{*}{ Men } & Frequencies & 213 & 139 & \multirow{3}{*}{352} \\
\hline & The expected frequency & 228.1 & 123.9 & \\
\hline & Percentage by age & 60.5 & 39.5 & \\
\hline \multirow{3}{*}{ Women } & Frequencies & 157 & 62 & \multirow{3}{*}{219} \\
\hline & The expected frequency & 141.9 & 77.1 & \\
\hline & Percentage by age & 71.7 & 28.3 & \\
\hline Total & Frequencies & 370 & 201 & 571 \\
\hline
\end{tabular}

$\mathrm{PCl}=$ percutaneous coronary intervention

Table 11. Distribution of acute myocardial infarction complications by gender

\begin{tabular}{|c|c|c|c|c|}
\hline \multicolumn{2}{|r|}{ Complications } & \multirow{2}{*}{$\begin{array}{c}\text { Men } \\
89\end{array}$} & \multirow{2}{*}{$\begin{array}{c}\text { Women } \\
56\end{array}$} & Total frequencies \\
\hline \multirow{3}{*}{ LVEF $<50 \%$} & Frequencies & & & \multirow{3}{*}{145} \\
\hline & The expected frequency & 89.4 & 55.6 & \\
\hline & Percentage by age & 61.4 & 38.6 & \\
\hline \multirow{3}{*}{ LV aneurysm } & Frequencies & 12 & 10 & \multirow{3}{*}{22} \\
\hline & The expected frequency & 13.6 & 8.4 & \\
\hline & Percentage by age & 54.5 & 45.5 & \\
\hline \multirow{3}{*}{ Mural thrombus } & Frequencies & 23 & 9 & \multirow{3}{*}{32} \\
\hline & The expected frequency & 19.7 & 12.3 & \\
\hline & Percentage by age & 71.9 & 28.1 & \\
\hline \multirow{3}{*}{ Pericardial effusion } & Frequencies & 62 & 40 & \multirow{3}{*}{102} \\
\hline & The expected frequency & 62.9 & 39.1 & \\
\hline & Percentage by age & 60.8 & 39.2 & \\
\hline \multirow{3}{*}{ Heart failure } & Frequencies & 123 & 67 & \multirow{3}{*}{190} \\
\hline & The expected frequency & 117.1 & 72.9 & \\
\hline & Percentage by age & 64.7 & 35.3 & \\
\hline \multirow{3}{*}{ Died } & Frequencies & 33 & 31 & \multirow{3}{*}{64} \\
\hline & The expected frequency & 39.4 & 24.6 & \\
\hline & Percentage by age & 51.6 & 48.4 & \\
\hline Total & Frequencies & 342 & 213 & 555 \\
\hline
\end{tabular}

LVEF = left ventricule ejection fraction; LV = left ventricule 


\section{DISCUSSION}

In our research, we have established certain differences in epidemiological, clinical and therapeutic characteristics of AMI between the two gender.

In patients with AMI we have verified more men than women (60.8 vs 39.2\%, $\chi 2=26.986$; $\mathrm{P}<0.001$ ) (table 1). These data are consistent with other results from recent studies where women also had less hospitalizations for AMI than men, but had a more unstable angina pectoris ${ }^{20-22}$

Our male and female patients are older than 60 years, and both sexes are equally represented. In patients under 60 years, there are more men than women ( 28.7 vs. $12.3 \%, \chi 2=21.327 ; P<0.001$ ) (table 2). The results of other surveys correlate with our results ${ }^{7}$.

Typical symptoms of $\mathrm{AMI}$ are more common in men (69.3 vs $61.2 \%)$, and atypical symptoms are more common in women (38.8 vs $30.7 \%$, $\chi 2=4.028 ; P=0.045$ ) (table 3). Our findings are similar to the results of other researchers where women also have atypical symptoms of CAD more often than men. Among these the most common are back pain and lower jaw pain, shortness of breath, nausea, fatigue, cough and palpitations ${ }^{23-26}$. Regarding cardiovascular risk factors our tested women had more often than men $\mathrm{AH}$ (82.4 vs 73.9\%, $\chi 2=5.685 ; P=0.017$ ) (table 4) and diabetes (41.0 vs $31.8 \%, \chi 2=5.053 ; P=0.025$ ) (table $5)$. These results also do not depart from the results of recent studies where women are more likely to have $\mathrm{AH}$ and diabetes ${ }^{27-30}$.

We have verified smoking in male patients with AMI more often than women (34.9 vs $21.6 \%$, $\chi 2=11.791 ; P=0.001$ ) (table 6). The same results where women have a lower prevalence of smoking than men were also reported by other authors, Johansson $(P<0.001)^{31}$ and Roger $(23.1$ vs $18.1 \%)^{32}$.

Our results regarding hyperlipidemia were not completely identical with the results of previous studies because we had an equal share of hyperlipidemia in men and women (47.2 vs. 45.4, $\chi 2=0.117 ; P=0.674$ ) (table 7). In other studies higher proportion of hyperlipidemia was diagnosed in women. For example, Emily also had a signifi- cantly higher hyperlipidemia in women than men (118.9 vs. $111.5 \mathrm{mg} / \mathrm{dL}$; $\mathrm{P}<0.001)^{33}$.

Localization of $A M I$ in our patients did not differ between males and females ( $\chi 2=2.708 ; P=0.608$ ) (table 8 ). But, unlike our results, Mieszcanska established a higher incidence of inferior AMI in men (44 vs $35 \%$; $P=0,03$ ) while the other localization of AMI between two gender represented equally ${ }^{34}$.

Regarding the time passed from the onset of AMI until arriving at the hospital ( $<6$ hours, 6-12 and

Acute myocardial infarction can be prevented by timely education on risk factors. By recognizing the character of the symptoms, the disease can be easily recognized outside the hospital. This is a condition for early hospital admission and treatment with more effective percutaneous coronary intervention than conservative therapy.

$>12$ hours), in our patients there was no significant difference in arrival at the hospital between men and women ( $\chi 2=1.839 ; P=0.399$ ) (table 9). These data are different from other results because women usually arrive later in the hospital after the beginning of symptoms. It is believed that women have more atypical symptoms which are often underestimated ${ }^{35-37}$. Therefore, we can be satisfied with a personal assessment of our female patients, as well as with an assessment of emergency medical assistance in the field because our women still come to the hospital at the optimum time from the onset of symptoms.

Our results have shown more men than women treated with $\mathrm{PCl}$ method, while women were exposed to conservative treatment method $(\chi 2=7.395 ; P=0.007)$ (table 10). These results are similar to the results of previous studies where women often have atypical symptoms that are more difficult to recognize ${ }^{38}$. Women also have more comorbidities and risk for side effects hence doctors do not decide to do $\mathrm{PCl}$ treatment ${ }^{39}$. By comparing the frequency of the most common complications of $\mathrm{AMI}$, we have an equal distribution between both gender ( $\chi 2=5.440$; $P=0.365$ ) (table 11). In the literature, the early mortality and a higher incidence of other compli- 
cations of $\mathrm{AMI}$ are more common in women ${ }^{40}$. Our women are not late in arriving at the hospital (table 9), and this is one of the conditions for reducing the incidence of post-infarction complications.

As a conclusion, we have verified more men than women in patients with AMI. AMI is more common over age of 60 and in younger patients men have more frequent AMI than women. Typical symptoms of $\mathrm{AMI}$ are more common in men, and atypical symptoms in women. Women have more often $\mathrm{AH}$ and diabetes and men are more often smokers. Hyperlipidemia is equaly present in both sexes. Localization of AMI in our patients did not differ between males and females. There was no significant difference in arrival at the hospital between men and women.

Men are more likely to receive $\mathrm{PCl}$ treatment, while women conservative therapy. The frequency of the complications of AMI are equal between both gender.

All these characteristics in our patients with AMI are similar to other studies. But, our women have less hyperlipidaemia. Are the reasons eating habits or genetics, remains to be tested in future studies. Our women are not late in an arrival at the hospital after the onset of AMI symptoms. Are the reasons in the education and good organization of the outpatient emergency medical assistance may be also the subject of future studies.

Conflicts of interest statement: the authors report no conflicts of interest.

\section{REFERENCES}

1. Murray CJ, Lopez AD. Alternative projections of mortality and disability by cause 1990-2020: Global Burden of Disease Study. Lancet 1997;349:1498-504.

2. Stone NJ, Robinson JG, Lichtenstein AH, Bairey Merz $\mathrm{CN}$, Blum CB, Eckel RH et al. 2013 ACC/AHA guideline on the treatment of blood cholesterol to reduce atherosclerotic cardiovascular risk in adults: a report of the American College of Cardiology/American Heart Association Task Force on Practice Guidelines. J Am Coll Cardiol 2014;63:2889-934.

3. Douglas PS, Ginsburg GS. Current concepts: the evaluation of chest pain in women. N Engl J Med 1996;334: 1311-5.

4. Summers R, Cooper GJ, Woodward LH, Finerty L. Association of atypical chest pain presentations by African-Americans and the lack of utilization of reperfusion therapy. Ethn Dis 2001;11:463-8.
5. Milner KA, Funk M, Arnold A, Vaccarino V. Typical symptoms are predictive of acute coronary syndromes in women. Am Heart J 2002;143:283-8.

6. Dorsch MF, Lawrence RA, Sapford RJ, Durham N, Oldham J, Greenwood DC et al. EMMACE Study Group, Poor prognosis of patients presenting with symptomatic myocardial infarction but without chest pain. Heart 2001;86:494-8.

7. Canto JG, Shlipak MG, Rogers WJ, Malmgren JA, Frederick PD, Lambrew CT et al. Prevalence, clinical characteristics and mortality among patients with myocardial infarction presenting without chest pain. JAMA 2000; 283:3223-9.

8. Lusiani L, Perrone A, Pesavento R, Conte G. Prevalence, clinical features and acute course of atypical myocardial infarction. Angiology 1994;45:49-55.

9. Lim SS, Vos T, Flaxman AD, Danaei G, Shibuya K, AdairRohani $\mathrm{H}$. A comparative risk assessment of burden of disease and injury attributable to 67 risk factors and risk factor clusters in 21 regions, 1990-2010: a systematic analysis for the Global Burden of Disease Study 2010. Lancet 2012;380:2224-60.

10. Lewington S, Clarke R, Qizilbash N, Peto R, Collins R. Age-specific relevance of usual blood pressure to vascular mortality: a meta-analysis of individual data for one million adults in 61 prospective studies. Lancet 2002;360:1903-13.

11. Sarwar N, Gao P, Seshasai SR, Gobin R, Kaptoge S, Di Angelantonio $\mathrm{E}$ et al. Diabetes mellitus, fasting blood glucose concentration, and risk of vascular disease: a collaborative meta-analysis of 102 prospective studies. Lancet 2010;375:2215-22.

12. Lindstrom J, Tuomilehto J. The diabetes risk score: a practical tool to predict type 2 diabetes risk. Diabetes Care 2003;26:725-31.

13. Prescott E, Hippe M, Schnohr P, Hein HO, Vestbo J. Smoking and risk of myocardial infarction in women and men: longitudinal population study. BMJ 1998;316: 1043-7.

14. Neaton JD, Blackburn $H$, Jacobs D, Kuller L, Lee DJ, Sherwin $\mathrm{R}$ et al. Serum cholesterol level and mortality findings for men screened in the Multiple Risk Factor Intervention Trial. Multiple Risk Factor Intervention Trial Research Group. Arch Intern Med 1992;152:1490500.

15. Stone PH, Raabe DS, Jaffe AS, Gustafson N, Muller JE, Turi ZG et al. Prognostic significance of location and type of myocardial infarction: independent adverse outcome associated with anterior location. J Am Coll Cardiol 1988;11:453-63.

16. Gruppo Italiano per lo Studio della Streptochinasi nell'Infarto Miocardico (GISSI), Effectiveness of intravenous thrombolytic treatment in acute myocardial infarction. Lancet 1986;1:397-402.

17. Schomig A, Mehilli J, Antoniucci D, Ndrepepa G, Markwardt C, Di Pede F et al. Beyond $12 \mathrm{~h}$ Reperfusion Alternative Evaluation (BRAVE-2) Trial Investigators. Mechanical reperfusion in patients with acute myocardial infarction presenting more than 12 hours from symptom onset: a randomized controlled trial, JAMA 2005;293:2865-72.

18. Mullasari AS, Balaji P, Khando T. Managing complications in acute myocardial infarction. J Assoc Physicians India 2011;59:43-8. 
19. Petz, B. Osnovne statističke metode za nematematičare. $5^{\text {th }}$ Edition. Jastrebarsko: Naklada Slap, 2004;258-9.

20. Lerner DJ, Kannel WB. Patterns of coronary heart disease morbidities and mortality in the sexes: a 26 year follow-up of the Framingham population Am Heart J 1986;111:383-90.

21. Hochman JS, Tamis JE, Thompson TD, Weaver WD, White HD, Van de Werf F et al. Sex, clinical presentation, and outcome in patients with acute coronary syndromes. N Engl J Med 1999;341:226-32.

22. Hsia J, Aragaki A, Bloch M, LaCroix AZ, Wallace R. Predictors of angina pectoris versus myocardial infarction from the women's health initiative observational study. Am J Cardiol 2004;93:673-8.

23. Goldberg RJ, O’Donnell C, Yarzebski J, Bigelow C, Savageau J, Gore JM. Sex differences in symptom presentation associated with acute myocardial infarction: a population-based perspective. Am Heart J 1998;136: 189-95.

24. DeVon HA, Zerwic JJ. The symptoms of unstable angina: do women and men differ? Nurs Res 2003;52:108-18.

25. Milner KA, Funk M, Richards $S$, Wilmes RM, Vaccarino $\mathrm{V}$, Krumholz HM. Gender differences in symptom presentation associated with coronary heart disease. Am J Cardiol 1999;84:396-9.

26. Penque $S$, Halm M, Smith M, Deutsch J, Van Roekel M, McLaughlin L et al. Women and coronary artery disease: relationship between descriptors of signs and symptoms and diagnostic and treatment course. Am J Crit Care 1998;7:175-82.

27. Chandra NC, Ziegelstein RC, Rogers WJ, Tiefenbrunn AJ, Gore JM, French WJ et al. Observations of the treatment of women in the United States with myocardial infarction: a report from the National Registry of Myocardial Infarction I. Arch Intern Med 1998;158:981-8.

28. Maynard C, Every NR, Martin JS, Kudenchuk PJ, Weaver WD. Association of gender and survival in patients with acute myocardial infarction. Arch Intern Med 1997;157:1379-84.

29. Canto JG, Rogers WJ, Chandra NC, French WJ, Barron $H V$, Frederick PD et al. National Registry of Myocardial Infarction 2 Investigators, The association of sex and payer status on management and subsequent survival in acute myocardial infarction. Arch Intern Med 2002; 162:587-93.

30. Blomkalns AL, Chen AY, Hochman JS, Peterson ED, Trynosky K, Diercks DB et al. CRUSADE Investigators, Gender disparities in the diagnosis and treatment of non-ST-segment elevation acute coronary syndromes: large-scale observations from the CRUSADE (Can Rapid Risk Stratification of Unstable Angina Patients Suppress
Adverse Outcomes With Early Implementation of the American College of Cardiology/American Heart Association Guidelines) National Quality Improvement Initiative. J Am Coll Cardiol 2005;45:832-7.

31. Johansson S, Bergstrand R, Ulvenstam G, Vedin A, Wilhelmsson $\mathrm{C}$, Wedel $\mathrm{H}$ et al. Sex differences in preinfarction characteristics and longterm survival among patients with myocardial infarction. Am J Epidemiol 1984;119:610-23.

32. Roger VL, Go AS, Lloyd-Jones DM, Adams RJ, Berry JD, Brown TM et al. American Heart Association Statistics Committee and Stroke Statistics Subcommittee. Heart disease and stroke statistics - 2011 update: a report from the American Heart Association. Circulation 2011; 123:18-209.

33. Schroeder EB, Bayliss EA, Daugherty SL, Steiner JF. Gender Differences in Cardiovascular Risk Factors in Incident Diabetes. Womens Health Issues 2014;24:61-8.

34. Mieszczanska H, Pietrasik G, Piotrowicz K, McNitt S, Moss AJ, Zareba W. Gender Related Differences in Electrocardiographic Parameters and Their Association with Cardiac Events in Patients After Myocardial Infarction. Am J Cardiol 2008;101:20-4.

35. Hurtado-Martínez J, Pinar-Bermúdez E, Teruel-Carrillo F, Gimeno-Blanes JR, Lacunza-Ruiz J, Valdesuso R et al. Inhospital and long-term mortality in women with acute myocardial infarction treated by primary angioplasty. Rev Esp Cardiol 2006;59:1113-22.

36. Velders MA, Boden $\mathrm{H}$, Van Boven AJ, Van der Hoeven $B L$, Heestermans AA, Cannegieter SC et al. Influence of gender on ischemic times and outcomes after ST-elevation myocardial infarction. Am J Cardiol 2013;111:312-8.

37. Dreyer RP, Beltrame JF, Tavella R, Air T, Hoffmann B, Pati PK et al. Evaluation of gender differences in Door-toBalloon time in ST-elevation myocardial infarction. Heart Lung Circ 2013;22:861-9.

38. Lawesson SS, Alfredsson J, Fredrikson M, Swahn E. A gender perspective on short- and long term mortality Int J Cardiol.in ST-elevation myocardial infarction--a report from the SWEDEHEART register. Int I Cardiol 2013; 168:1041-7.

39. Jortveit J, Elise R, Govatsmark S, Langørgen J, Hole T, Mannsverk $J$ et al. Gender differences in the assessment and treatment of myocardial infarction. Tidsskr Nor Legeforen 2016;136:1215-22.

40. Laufer-Perl M, Shacham $Y$, Letourneau-Shesaf S, Priesler $\mathrm{O}$, Keren G, Roth R et al. Gender-Related Mortality and In-Hospital Complications Following ST-Segment Elevation Myocardial Infarction: Data From a Primary Percutaneous Coronary Intervention Cohort. Clinical Cardiology 2015;38:145-9. 